\title{
Self-directed Learning via Contemplative Teaching to Promote Reading Comprehension Ability
}

\author{
Fatemeh Giveh ${ }^{1}$ \\ ${ }^{1}$ Faculty of Persian Literature and Foreign Languages, Islamic Azad University South Tehran Branch, Tehran, \\ Iran \\ Correspondence: Fatemeh Giveh, Faculty of Persian Literature and Foreign Languages, Islamic Azad University \\ South Tehran Branch, Tehran, Iran.
}

Received: December 29, 2017 Accepted: November 10, 2018 Online Published: November 14, 2018

doi: $10.5539 /$ elt.v11n12p58

URL: https://doi.org/10.5539/elt.v11n12p58

\begin{abstract}
The present study tried to investigate one of the options for improving self-directed learning in Iranian EFL learners, i.e., contemplative L2 instruction with a flavor of transformative instruction. Accordingly, it adopted a quasi-experimental design to investigate the influential effects that contemplative teaching would exert on Iranian EFL learners' L2 self-directed learning and reading comprehension abilities. To this end, two groups of Iranian EFL learners were taught on the L2 through either contemplative teaching (Experimental Group) or a traditional method (Control Group). The results of the study indicated that contemplative teaching, accompanied with transformative instruction, would in fact have significant effects on Iranian EFL learners' L2 autonomy, i.e., self-directed L2 learning, and L2 reading comprehension skills. In addition, the analysis of the qualitative indicated that the participants in the Experimental Group held positive attitudes towards contemplative and transformative L2 instruction and believed these instructional strategies would create a supporting and viable classroom atmosphere. The findings of this study would have significant implications for both theory and practice on L2 contemplative teaching, self-directed learning, and reading comprehension.
\end{abstract}

Keywords: self-directed learning, contemplative teaching, reading comprehension, transformative education

\section{Introduction}

English Language schools and EFL instructors in Iran have lived over the past three decades with a serious concern over the inclusion of meta-techniques, skills, and theories to enrich their English programs to foster and nurture more productive, rewarding, and successful students. Following the same line of thought, in past decade, we have been the witness of dire need for the use of transformative education and contemplative teaching to accompany prevalent teaching programs to depict and safeguard ESL learners' effectiveness and success. The other way round, fostering autonomous (self-directed) EFL learners is of great importance to language educators everywhere. Confidently enough, the idea of transformative teaching as well as contemplative teaching can be the core part of the modern EFL contexts everywhere, especially Iran.

Emphasis on learner autonomy, independence, and self-reliance is heard everywhere in the field of Second Language (L2) teaching and learning and language teachers are strongly encouraged to improve these aspects in their L2 learners (see Dörnyei, 2005). Consequently, practitioners have come to notice that the improvement of these aspects can be best served through self-directed learning (SDL). However, there is disagreement as to how a self-directed learning program can be deployed. Houle (1961) presented the notion of SDL to the research community with his text, The Inquiring Mind. Tough (1971) advanced understanding of the self-directed learner by developing an interview protocol with which he collected descriptions of the number, duration, and scope of learning projects of numerous self-directed learners. Knowles $(1975$, p. 18) offered a widely accepted definition of SDL: in its broadest meaning, self-directed learning describes a process in which individuals "take the initiative, with or without the help of others, in diagnosing their learning needs, formulating learning goals, identifying human and material resources for learning, choosing and implementing appropriate learning strategies, and evaluating learning outcomes".

The present study was conducted with the purposes of investigating one of the options for improving self-directed learning in Iranian learners of English as a Foreign Language (EFL); i.e., contemplative L2 instruction with a flavor of transformative instruction. This study suffered from some imposed limitations. 
Observations definitely were not satisfactorily adequate, owing to the dearth of time and budget; in addition, sample truncation, in effect, would happen due to the high cost the process of sampling poses (True experimental was impossible). In this study, generalizability would be at best questionable, because quasi-experimental design could not move so far. Some other latent factors including tiredness, stress, and some personal problems affected the application of contemplative teaching and transformative learning. Such impact was out of the researcher's control. Participants also did not cooperate fully with the researcher and the language school imposed some constraints to the researcher.

The researcher also restricted this study. Since she wanted to define the borderlines of the study and avoid possible imposed limitations for generalization purposes. It is safe to say that the investigation focused only on the reading skill not any other language skills. Only female students took part in this research, because the researcher did not plan to teach male students. The EFL learners were all intermediate students at a well-known language school in Tehran. They were selected from amongst EFL learners' between 19 and 30. The participants have been selected based on snowball sampling technique.

It is noteworthy that the present study is significant, because upon its completion, the participants have grown as self-directed and autonomous EFL learners to approach reading comprehension tasks. This can be generalizable to other contexts where learners are looking for ways to stand on their own feet. Transformative teaching and contemplative teaching have come to be the two interrelated concepts teachers and learners can avail from to develop their reading comprehension skills deeper and stronger. Therefore, both transformative and contemplative teaching have been of great value and importance to the educational system, which involves language teachers, student's families, language schools, colleges, universities, and most importantly language learners.

\section{Purpose of the Study}

This study adopted a quasi-experimental research design to investigate the influential effects that contemplative teaching would exert on Iranian EFL learners' L2 self-directed learning and reading comprehension abilities. For this purpose, two groups of Iranian EFL learners were taught on the L2 through either contemplative teaching (Experimental Group) or a traditional method (Control Group). To trace the effects of these two approaches to L2 teaching on L2 self-directed learning and reading comprehension, a pretest-posttest procedure was undertaken. Accordingly, the goal of this study was threefold. Firstly, the researcher refined the current understanding of contemplative teaching, transformative education, and learner's autonomy (self-directed learning). Secondly, she tried to understand how such factors could help the EFL students become self-directed in dealing with reading comprehension skill. Finally, the researcher cast light on the concept of transformative learning in EFL context to help both teachers and learners discover the hidden sides of their personality. Accordingly, the researcher dealt with five following questions:

RQ1: Does the application of contemplative teaching as a method in an EFL class reliably affect the students to turn into self-directed learners, as compared to students in conventional EFL classes? (Quantitative)

RQ2: Does self-directed learning significantly improve students' reading comprehension skills, as compared to those students in conventional EFL classes? (Quantitative)

RQ3: What is the students' attitude toward self-directed learning? (Qualitative)

RQ4: What problems students might face within contemplative teaching setting? (Qualitative)

RQ5: In what ways, does transformative learning and teaching change classroom atmosphere?

In order to investigate the above research questions, the following two null hypotheses were developed:

H01: The application of contemplative teaching as a method in an EFL class does not reliably affect the students to turn into self-directed learners, as compared to students conventional EFL classes. (Quantitative)

H02: Self-directed learning does not significantly improve students' reading comprehension skills, as compared to those students in conventional EFL classes. (Quantitative)

\section{Methodology}

\subsection{Participants}

The researcher invited and recruited 96 participants by means of snowball sampling technique. Out of these participants, 65 agreed to partake in the research. They were all students of an Institute in Tehran. They were only female EFL learners enrolled Translation Studies, Literature, Teaching of English as a Foreign Language, and Linguistics. As a small-scale research, the researcher formed the sample population, representing the target 
population for the purpose of generalization. After administrating Preliminary English Test (PET), a standardized test that measures language proficiency designed and validated by Cambridge University, Educational Services Overseas Limited (ESOL) department, to be used for homogenization of the participants, the researcher then formed two parallel experimental groups and two parallel control groups and named them as E1, E2, C1, and C2. E1 holds 16, E2 holds 16, $\mathrm{C} 1$ holds 17, and finally $\mathrm{C} 2$ holds 16 students that make up 65 participants. Therefore, out of 96 selected candidates 31 candidates dropped the research classes in the first square of the study. All groups took the reading test (pretest) extracted from Preliminary English Test (PET). Later, they attended the reading classes, studying "Reading Book O" by McMillan grade six. They were assumed to be at intermediate level according to the successful completion of the test. All participants were Persian speakers whose age varied between 19 and 30 .

\subsection{Instrumentation}

To collect data, the researcher employed the following instruments to measure the general language proficiency, reading comprehension ability, as well as self-directed learning.

1). To measure and determine the participants' level of general English language proficiency particularly reading ability, they were required to do a standard test. Thus, PET test was used which is an exam for people who can use every day written and spoken English at an intermediate level. PET is suitable for everyone who can use English to deal with everyday event, read simple textbooks or magazine articles, and write letters on familiar objects and takes notes in a meeting. A version of PET tests was used as pretest and another version as the posttest. Throughout the test, candidates are assessed on their language skills, not their personality, intelligence, or knowledge of the world. They must, however, be willing to develop the conversation, where appropriate, and respond to the tasks set. Prepared speeches are not acceptable. Candidates were assessed on their individual performance and not in relation to each other.

PET exam takes one hour and 30 minutes to accomplish writing and reading. Reading includes 5 parts and 35 questions. Writing includes three parts and seven questions. The purpose was to show students could read and understand the main points from signs, journals, newspapers and magazines, and could use vocabulary and structure, correctly. Fifty percent of score was achieved through reading and writing. Listening took 30 minutes, plus 6 minutes' transfer time. It had 4 parts and 25 questions. It required the students to be able to follow and understand a range of spoken materials including announcements and discussions about everyday life. Twenty five percent of score was achieved through listening. Finally, speaking took 10-12 minutes per pair of candidates including four parts.

Throughout the test, candidates were assessed on their language skills, not their personality, intelligence, or knowledge of the world. They must, however, be prepared to develop the conversation, where appropriate, and respond to the tasks set. Prepared speeches were not acceptable. Candidates were assessed on their own individual performance and not in relation to each other. Both examiners assessed the candidates, according to criteria, which were interpreted at PET level.

2). The researcher administered the pretest of reading proficiency to both groups. The reading tests for both groups of candidates were two parallel reading comprehension tests of PET (two different versions of PET). The two reading comprehension questions were administered at the end of the research process to the two groups of participants in a reverse way.

3). The researcher employed SDL questionnaire to measure the participants' level of independency and autonomy in language learning. The questionnaire was employed two times throughout the study. SDL was used once before the treatment of contemplative teaching and reading comprehension lessons, and once after treatment.

\subsection{Variables}

In this study, contemplative teaching acted as the independent variable that was supposed to change the participants' mental and behavioral conceptions to turn into self-directed learners. In addition, self-directed learning would later act as the second independent variable that affects students' reading comprehension ability. On the other hand, reading comprehension ability was considered the dependent variable, because it was affected by the impact of both contemplative teaching and learning along with self-directed learning.

\subsection{Treatment}

The treatment was carried out for 12 sessions during the fall semester of 2016. The students of these classes were assured to be the homogeneous level of English proficiency by means of PET test, then a class was assigned to serve as experimental group, while, the other as control group. Both classes were held two days a week on even 
days for 12 sessions. Experimental group class started from 5:00 p.m. to 6:30 p.m., while control group class started from 6:45 p.m. to 8:15 p.m. Each session took about 90 minutes. A teacher was recruited as the teacher of both experimental and control groups. The participants received 1 hour and 30 minutes treatment including 15 minutes of discussion using the techniques of contemplative teaching especially portraiture every session. To implement the treatment, the teacher brought a reading text with an engaging topic to both groups every session. The text contained topics of general interest. The researcher herself out of PET course materials chose the words. At the beginning of each session, the teacher engaged the students and provided them with topics related to self-enhancement. Then, the students took notes of the hows of improving their lifestyle, thinking, attitude, defiance, intellect, and reasoning. Next, the copies of reading passages and reading comprehension questions were handed out to the whole participants. Students listened to audio program of the passage. Then, they were supposed to answer true or false or multiple choice reading comprehension questions.

\subsection{Design of the Study}

There are different kinds of designs that fit into various studies. The research question in a study determines the design of the study. According to Hatch and Farhady (1982, p. 22), if a study has the following characteristics, "the study is true - experimental. First, control group is present, secondly, random selection is employed, and thirdly, pretest is administered. These characteristics alleviate the problems related to external and internal validity we had in pre- experimental designs". However, meeting all the aforementioned characteristics seems quite unlikely in a study. In the present study, because the participant did not randomly assigned to the groups, the student were determined, before the beginning of the treatment; therefore, the best design which was conducted for this study was quasi-experimental design.

The research question in a study determines the design of the study. This research aimed at finding the effect and impact of contemplative teaching and learning (education) on Iranian EFL students to turn into self-directed learners or autodidacts. Contemplative education integrates introspection and experiential learning into academic study to support academic and social engagement, develop self-understanding, as well as analytical and critical capacities, and cultivate skills for engaging constructively with others. Self-directed learners or autodidacts were instructed in the experimental group class like the students who took part in the control group class to approach reading passages of PET materials. Hatch and Farhady (1981, p. 24) suggest that quasi-experimental designs are practical compromises between true experimentation and the nature of human language behavior which we wish to investigate. Such designs are vulnerable to some of the questions of internal and external validity.

Classroom research needs to be conducted in pedagogical environment in which so many factors as the students' age and how the students are placed in classes and other variables like that is being faced. Mostly, it was impossible for the researcher to assign students randomly to language classes. Some students were placed in classes both on the basis of some criterion (e.g., scores on placement test, successful completion of the prior course, or even self-selection according to the time the class in offered (Hatch \& Farhady, 1996). Due to such issues assigning two groups, one as control group and one as experimental based on true randomization is often impossible (Hatch \& Farhady, 1996). Therefore, our pre-experimental design, the intact group design was chosen to select the groups. As it was mentioned in Hatch and Farhady (1996), both experimental and control groups will receive a posttest, but the experimental group will receive the treatment while the control group does not. They mentioned also that the presence of the control group in this design eliminates some of the problems related to internal validity. Nonetheless, generalizing the results of the study beyond our experiment should be done with care, because the participants have not been randomly assigned to the two groups, thus external validity is at best questionable. After the two groups were assigned using intact group design, it was the right time to conduct the experiment.

\subsection{Procedure}

The researcher primarily started her study by recruiting and inviting participants using snowball sampling. The study was carried out based on the following stepwise procedure:

1). Homogenization: Students, at the beginning, were homogenized according to their level of language proficiency. To do so, she administered PET test, a standardized version, with clear reliability and validity indices.

2). Classification: The four classes then were named as Experimental Group, and Control Group. The total number of students in both groups was 65 .

3). Pretesting: The two selected groups were first interviewed and were asked to fill out the questionnaire (SDL) and then they were asked to take the reading test based in the PET materials. 
4). Treatment: Experimental Group (EG) received contemplative practices as well as self-directed education along with the components. The Control Group (CG) was considered as the placebo group and therefore received the conventional teaching program of reading comprehension.

5). Statistical Test Phase 1: The scores obtained in pretest to measure reading ability of the participants were measured and then analyzed.

6). Treatment Period: Two classes received treatment for almost three months. The researcher for later interpretation recorded every single change in classroom.

7). Post Testing: For analyzing the effects of treatments during three months, a parallel test of reading section of PET were given to students to measure the amount of change in students reading ability.

8). Posttest Measurement: the amount of students' scores was measured ANCOVA analysis and the teacher was able to consider an appropriate score based on students' abilities.

9). Interviewing: two kinds of interview were run to find out how students feel about contemplative teaching and learning as well as self-directed education. The teachers did the formal interview, whereas the informal interview was carried out when students talked to each other about the program.

10). To Analyze the Data Obtained: the researcher employed Independent Samples t-test to compare the two groups' means on the proficiency test in order to homogenize them. An analysis of covariance was run to compare the two groups on the pretest, while controlling for the possible effects of the pretest in order to probe the first research question. An analysis of covariance was run to compare the two groups on the pretest of reading comprehension, while controlling for the possible effects of the pretest in order to probe the second research question. KR-21 reliability indices were employed to compute for the questionnaires and tests. The construct validity of the instruments was also probed by means of exploratory factor analysis (EFA).

\subsection{Procedure for Experimental Groups}

Experimental Groups were under transformative education plus contemplative teaching leading to self-directed learning. Based on the transformative learning theory, students change in three ways; namely, psychological, convictional, and behavioral. The researcher and teacher embarked on using some techniques to help students step into a different world. Using a catalog, the researcher provided the students up with the nature of transformative learning. To set the tone, the teacher combined the classroom with the music, designed the class with some colored posters of nature, and used water and wooden objects to give students a sense of nature. This was followed later by the practice of Yoga teacher who was professional in teaching Yoga and meditation to the beginners. In the experimental classes, she demonstrated a sense of redemption and freedom from one's physic. Put differently, she helped students find a way to lower their psychological inhibitions to set their spirit and soul free from the cares of life. Practically speaking, the yoga teacher taught the students to control their breathing in order to feel their own presence in time. They were also trained how to control the movements of their stomach and chest muscles in order to make the breathing deeper and more effective. She also used music and largo speech tone to lead the students mind and soul to feel they exist at the moment of speaking. Mostly, the yoga teacher trained the mind and emotions of the candidates to help them feel their presence in the moment of speaking. This led the students towards a better learning in the class and out of the class context.

\subsection{Procedure for Control Groups}

Control Groups were under conventional reading class in which lack of contemplative teaching and self-directed learning were considered. The researcher herself took part in control classes only for one session. The students did not receive the full training of Yoga teachers. Only the researcher and the reading teacher handled the class. The researcher provided the students with some theoretical insights about contemplation and self-directed learning without any reference to practical techniques; however, it was not quite helpful and motivating. The whole semester was handled and managed by the reading teacher in the way previously defined and explained.

\section{Results of the Study}

\subsection{Preliminary Data Analysis (Testing Normality)}

The obtained data form the instruments employed in this study (PET, SDL, PET Reading pre- and post-tests) were primarily analyzed by employing independent-samples t-test and one-way analysis of covariance (one-way ANCOVA).

It should be noted here that besides ANCOVA's two explicit assumptions of linearity and homogeneity of regression slopes, which depict the linear relationship of the numerical values obtained after administration of the tests and the sameness of the scores obtained. Two other common assumptions should be met; normality and 
homogeneity of variances.

Although in the preliminary analysis, the assumption of homogeneity of variances is violated, there is no need to worry because none of the sample sizes is 1.5 times larger than the other one (Stevens, 2009). As displayed in Table 1, the assumption of normality was met. The absolute values of the ratios of skewness and kurtosis over their respective standard errors were lower than 1.96. In addition, the ratios for skewness do not exceed 1.06, and the counterparts of kurtosis do not exceed 0.4. Both maximum values are still below 1.96.

Table 1. Descriptive statistics; testing normality assumption

\begin{tabular}{lllllllll}
\hline \multirow{2}{*}{ Group } & & $\mathrm{N}$ & \multicolumn{6}{c}{ Skewness } \\
\cline { 3 - 8 } & & Statistic & Statistic & Std. Error & Ratio & Statistic & Std. Error & Ratio \\
\hline \multirow{6}{*}{ Experimental } & PET & 32 & -.234 & .414 & -0.57 & -1.256 & .809 & -1.55 \\
& Pre-SD & 32 & -.199 & .414 & -0.48 & -.884 & .809 & -1.09 \\
& Post-SD & 32 & .345 & .414 & 0.83 & -.291 & .809 & -0.36 \\
& Pre-RC & 32 & .439 & .414 & 1.06 & .070 & .809 & 0.09 \\
& Post-RC & 32 & -.393 & .414 & -0.95 & -.465 & .809 & -0.57 \\
\hline \multirow{5}{*}{ Control } & PET & 33 & -.161 & .409 & -0.39 & -1.273 & .798 & -1.60 \\
& Pre-SD & 33 & -.367 & .409 & -0.90 & .177 & .798 & 0.22 \\
& Post-SD & 33 & .026 & .409 & 0.06 & -.137 & .798 & -0.17 \\
& Pre-RC & 33 & -.038 & .409 & -0.09 & -.581 & .798 & -0.73 \\
& Post-RC & 33 & .263 & .409 & 0.64 & .318 & .798 & 0.40 \\
\hline
\end{tabular}

\subsection{PET General Language Proficiency Test}

As mentioned above, the researcher administered the general language proficiency test (PET) to 96 participants in the first square of the analysis. Based on the mean obtained $(\mathrm{M}=21.91)$ plus and minus one standard deviation $( \pm \mathrm{SD}=6.35)$; she selected 65 participants to partake in the main study. To approve of the reliability of the PET test, KR-21 reliability index was employed and the results obtained was .88 (see Table 2).

Table 2. Descriptive statistics; PET Test

\begin{tabular}{lllll}
\hline & $\mathrm{N}$ & Mean & Std. Deviation & Variance \\
\hline PET & 96 & 21.91 & 6.351 & 40.338 \\
KR-21 & .88 & & & \\
\hline
\end{tabular}

The index obtained is pretty close to 1 which is a perfect reliability index. In other words, the PET test employed is highly reliable and the scores it produced are quite consistent.

In order to prove that the experimental and control groups were homogenous, the researcher ran an independent-samples t-test. This was done to compare the experimental and control groups' means on the PET test in order to prove that the two groups were at the same level of general language proficiency prior to the administration of the treatments. As displayed in Table 3 below, the experimental $(\mathrm{M}=21.81, \mathrm{SD}=4.23)$ and control $(\mathrm{M}=22.33, \mathrm{SD}=4.36)$ groups' means differed by .53 unites on the PET test.

Table 3. Descriptive statistics; PET Test by groups

\begin{tabular}{lllll}
\hline Group & $\mathrm{N}$ & Mean & $\begin{array}{l}\text { Std. } \\
\text { Deviation }\end{array}$ & $\begin{array}{l}\text { Std. Error } \\
\text { Mean }\end{array}$ \\
\hline Control & 33 & 22.33 & 4.364 & .760
\end{tabular}




\begin{tabular}{lllll}
\hline Experimental & 32 & 21.81 & 4.231 & .748
\end{tabular}

The results of the independent-samples t-test $(\mathrm{t}(63)=.488, \mathrm{p}=.627,95 \%$ CI $[-1.61,2.65], \mathrm{r}=.061$, representing a weak effect size) (see Table 4), indicated that there was not any significant difference between the two groups' means on the PET test. Thus, it can be concluded that they were at the same level of general language proficiency prior to the main study.

Table 4. Independent-samples test; PET by groups

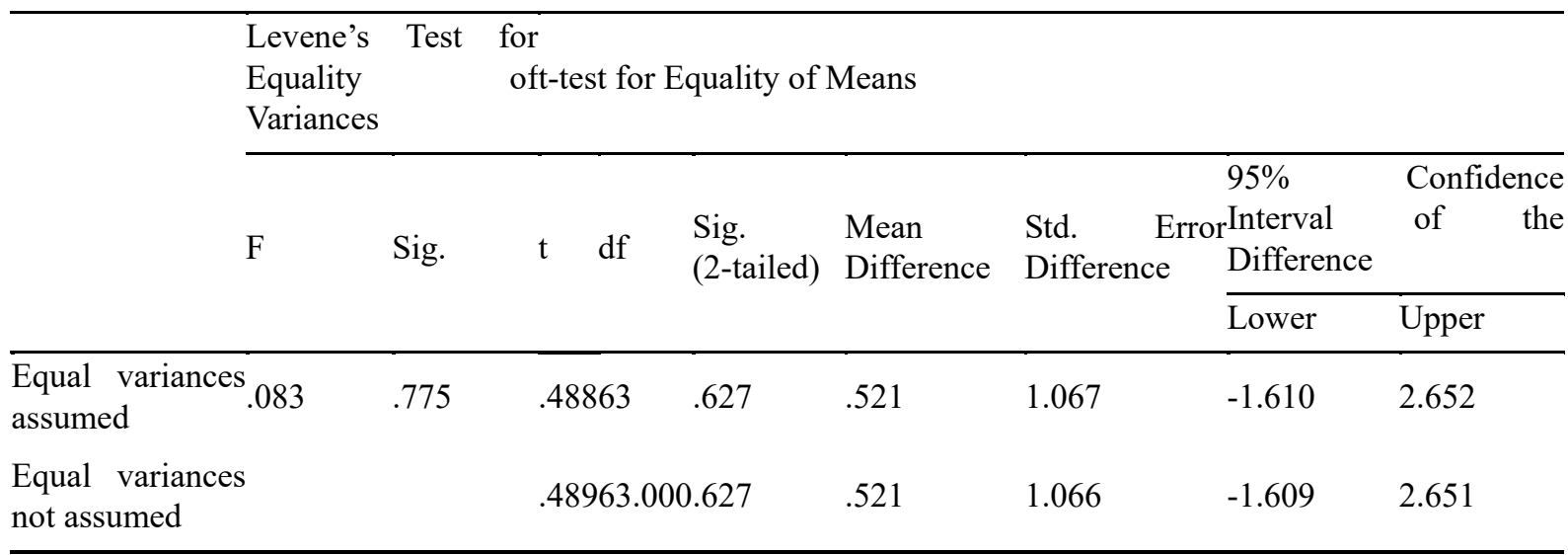

As displayed in Table 4 and Figure 1, the results of the Levene's test of homogeneity of variances was not significant $(\mathrm{F}=.083, \mathrm{p}=.775)$; that was why the statistics reported on the first row of Table 4; i.e., "Equal variances assumed was reported.

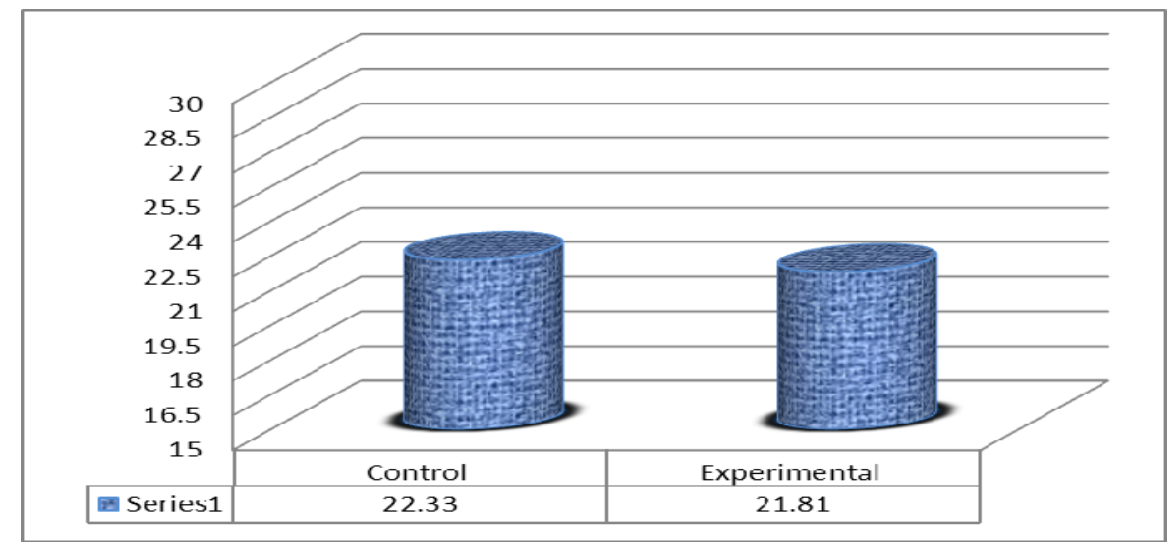

Figure 1. Means on PET by groups

The application of contemplative teaching as a method in an EFL class does not reliably affects the students to turn into self-directed learners as compared to students in conventional EFL classes. To testify the null hypothesis, the researcher employed one-way ANCOVA analysis. One-way ANCOVA was run to compare the experimental and control groups' means on the posttest of self-directed learners, while controlling for the possible effects of the pretest. ANCOVA has two specific assumptions; linear relationship between the covariate (pretest) and the posttest; and homogeneity of regression slopes.

Based on the results displayed in Table $5,(\mathrm{~F}(1,52)=142.497, \mathrm{p}=.000)$ indicated that the statistical assumption that the relationship between the covariate and posttest was not linear was rejected. In other words, there was a linear relationship between the pretest and posttest of self-directed learners. 
Table 5. ANCOVA Test of linear relationship between covariate and dependent variables

\begin{tabular}{llllll}
\hline & & Sum of Squares & df Mean Square & F & Sig. \\
\hline \multirow{2}{*}{ Between Groups } & (Combined) & 45253.276 & 123771.106 & 12.488 & .000 \\
& Linearity & 43030.531 & 143030.531 & 142.497 & .000 \\
& Deviation from Linearity & 2222.745 & 11202.068 & .669 & .761 \\
\hline Within Groups & & 15702.663 & 52301.974 & & \\
\hline Total & 60955.938 & 64 & \\
\hline
\end{tabular}

The assumption of homogeneity of regression slopes was investigated through the non-significant interaction between the covariate and the independent variable. As displayed in Table 6, there was a non-significant interaction between the pretest and independent variable $(\mathrm{F}(1,61)=1.34, \mathrm{p}=.251$, partial $\eta 2=.022$ representing a weak effect size); hence, homogeneity of regression slopes is low.

Table 6. Tests of between-subjects effects; testing homogeneity of regression slopes

\begin{tabular}{|c|c|c|c|c|}
\hline Source & Type III Sum of Squares & df Mean Square & $\mathrm{F}$ & Sig. Partial Eta Squared \\
\hline Group & 66.328 & 166.328 & 386 & .537.006 \\
\hline Pre-SDL & 41060.988 & 141060.988 & 238.684 & .000 .796 \\
\hline Group * Pre-SDL & 230.912 & 1230.912 & 1.342 & .251 .022 \\
\hline Error & 10493.855 & 61172.030 & & \\
\hline Total & 884625.000 & 65 & & \\
\hline
\end{tabular}

The assumption of homogeneity of variances was also met $(\mathrm{F}(1,63)=.391, \mathrm{p}=.534)$ (see Table 7).

Table 7. Levene's test of equality of error variances

\begin{tabular}{llll}
\hline F & df1 & df2 & Sig. \\
\hline .391 & 1 & 63 & .534 \\
\hline
\end{tabular}

As displayed in Table 8, the experimental group $(\mathrm{M}=123.27, \mathrm{SE}=2.32)$ had a higher mean than the control group $(\mathrm{M}=102.18, \mathrm{SE}=2.29)$ on the posttest of self-directed learning (SDL), after controlling for the possible effect of the pretest.

Table 8. Descriptive statistics; posttest of self-directed learning by groups by pretest

\begin{tabular}{lllll}
\hline \multirow{2}{*}{ Group } & Mean & \multirow{2}{*}{ Std. Error } & \multicolumn{2}{l}{$95 \%$ Confidence Interval } \\
\cline { 4 - 5 } & & & Lower Bound & Upper Bound \\
\hline Experimental & $123.276 \mathrm{a}$ & 2.327 & 118.625 & 127.928 \\
Control & $102.187 \mathrm{a}$ & 2.291 & 97.606 & 106.767 \\
\hline
\end{tabular}

a. Covariates appearing in the model are evaluated at the following values: Pre-SD $=95.62$.

The results of one-way ANCOVA $(F(1,62)=41.62, p=.000$, partial $\eta 2=.402$ representing a large effect size $)$ (see Table 9 and Figure 2) indicated that the experimental group significantly outperformed the control group on the posttest of self-directed learning (SDL) after controlling for the possible effect of the pretest. Thus, the first null-hypothesis holds that "the application of contemplative teaching as a method in an EFL class does not reliably affect the students to turn into self-directed learners as compared to students in conventional EFL classes" was rejected. 
Table 9. Tests of between-subjects effects; posttest of self-directed learning by groups by pretest

\begin{tabular}{|c|c|c|c|c|}
\hline Source & Type III Sum of Squares & df Mean Square & $\mathrm{F}$ & Sig. Partia Eta Squared \\
\hline Pre-SDL & 40831.247 & 140831.247 & 236.046 & $.000 \quad .792$ \\
\hline Group & 7200.640 & 7200.640 & 41.627 & $.000 \quad .402$ \\
\hline Error & 10724.767 & $62 \quad 172.980$ & & \\
\hline Total & 884625.000 & 65 & & \\
\hline
\end{tabular}

The significant F-value associated with the pretest of self-directed learning $(F=236.04, p=.000)$ indicated that it was correctly selected as a covariate.

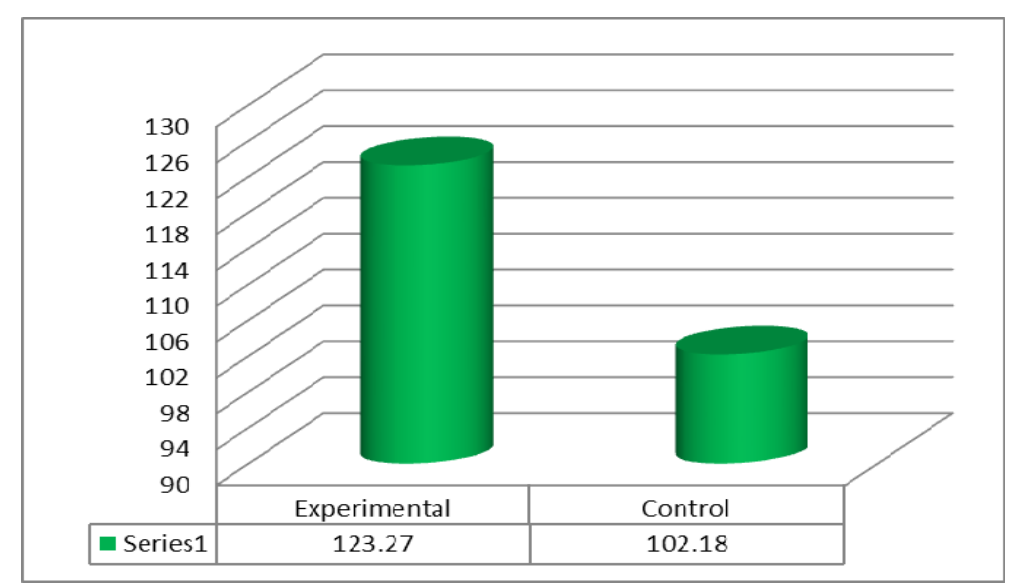

Figure 2. Means on posttest of self-directed learning by groups by pretest

The second null hypothesis indicates that self-directed learning does not significantly improve students' reading comprehension skills as compared to those students in conventional EFL classes. A one-way ANCOVA was run to compare the experimental and control groups' means on the posttest of Reading Comprehension (RC), while controlling for the possible effects of the pretest. Based on the results displayed in Table 10, $(\mathrm{F}(1,52)=149.72$, $\mathrm{p}=.000)$ indicated that the statistical assumption that the relationship between the covariate and posttest of RC was not linear was rejected. In other words, there was a linear relationship between the pretest and posttest of RC.

Table 10. ANCOVA test of linear relationship between pretest and posttest of reading comprehension

\begin{tabular}{|c|c|c|c|c|c|}
\hline & & Sum of Squares & df Mean Square & $\mathrm{F}$ & Sig. \\
\hline & (Combined) & 1811.652 & 17106.568 & 9.873 & .000 \\
\hline \multirow[t]{2}{*}{ Between Groups } & Linearity & 1616.132 & $\begin{array}{ll}1 & 1616.132\end{array}$ & 149.721 & .000 \\
\hline & Deviation from Linearity & 195.520 & 1612.220 & 1.132 & .355 \\
\hline Within Groups & & 507.333 & $47 \quad 10.794$ & & \\
\hline Total & & 2318.985 & 64 & & \\
\hline
\end{tabular}

As displayed in Table 11, there was a non-significant interaction between the pretest and independent variable ( $\mathrm{F}$ $(1,61)=3.61, p=.062$, partial $\eta 2=.056$ representing a weak effect size); hence, homogeneity of regression slopes. 
Table 11. Tests of between-subjects effects; testing homogeneity of regression slopes

\begin{tabular}{|c|c|c|c|c|}
\hline Source & Type III Sum of Squares & df Mean Square & $\mathrm{F}$ & Sig. Partial Eta Squared \\
\hline Group & 9.939 & 19.939 & 4.024 & .049.062 \\
\hline Pre-RC & 1649.385 & $1 \quad 1649.385$ & 667.788 & .000 .916 \\
\hline Group * Pre-RC & 8.940 & 18.940 & 3.619 & .062 .056 \\
\hline Error & 150.665 & 612.470 & & \\
\hline Total & 33735.000 & 65 & & \\
\hline
\end{tabular}

The assumption of homogeneity of variances was not met $(F(1,63)=9.59, p=.003)$ (see Table 12). As it was mentioned above; there was no need to worry about the violation of this assumption, because the ratio of the larger sample size over the smaller one (i.e., 33/32=1.02), was lower than 1.5. (Stevens, 2009).

Table 12. Levene's test of equality of error variances

\begin{tabular}{llll}
\hline $\mathrm{F}$ & $\mathrm{df1}$ & $\mathrm{df2}$ & Sig. \\
\hline 9.591 & 1 & 63 & .003 \\
\hline
\end{tabular}

As displayed in Table 13, the experimental group $(\mathrm{M}=24.92, \mathrm{SE}=.28)$ had a higher mean than the control group $(\mathrm{M}=19.13, \mathrm{SE}=.27)$ on the posttest of $\mathrm{RC}$ after controlling for the possible effect of the pretest.

Table 13. Descriptive statistics; posttest of reading comprehension by groups by pretest

\begin{tabular}{lllll}
\hline \multirow{2}{*}{ Group } & \multirow{2}{*}{ Mean } & \multirow{2}{*}{ Std. Error } & \multicolumn{2}{l}{$95 \%$ Confidence Interval } \\
\cline { 5 - 5 } & & & Lower Bound & Upper Bound \\
\hline Experimental & $24.921 \mathrm{a}$ & .284 & 24.354 & 25.488 \\
Control & $19.137 \mathrm{a}$ & .279 & 18.579 & 19.696 \\
\hline
\end{tabular}

a. Covariates appearing in the model are evaluated at the following values: Pre-RC $=19.77$.

As displayed in Table 14 and Figure 3, the results of one-way ANCOVA $(F(1,62)=211.02, p=.000$, partial $\eta 2$ $=.773$, representing a large effect size) indicated that the experimental group significantly outperformed the control group on the posttest of $\mathrm{RC}$, after controlling for the possible effect of the pretest. Thus, the second null-hypothesis was rejected.

Table 14. Tests of between-subjects effects; posttest of reading comprehension by groups by pretest

\begin{tabular}{|c|c|c|c|c|c|}
\hline Source & Type III Sum of Squares & df Mean Square & $\mathrm{F}$ & Sig. & Partial Eta Squared \\
\hline Pre-RC & 1644.129 & $1 \quad 1644.129$ & 638.676 & .000 & .912 \\
\hline Group & 543.248 & 1543.248 & 211.029 & . 000 & .773 \\
\hline Error & 159.605 & $62 \quad 2.574$ & & & \\
\hline Total & 33735.000 & 65 & & & \\
\hline
\end{tabular}

The significant F-value associated with the pretest of $\mathrm{RC}(\mathrm{F}=638.67, \mathrm{p}=.000)$ indicated that it was correctly selected as a covariate. 


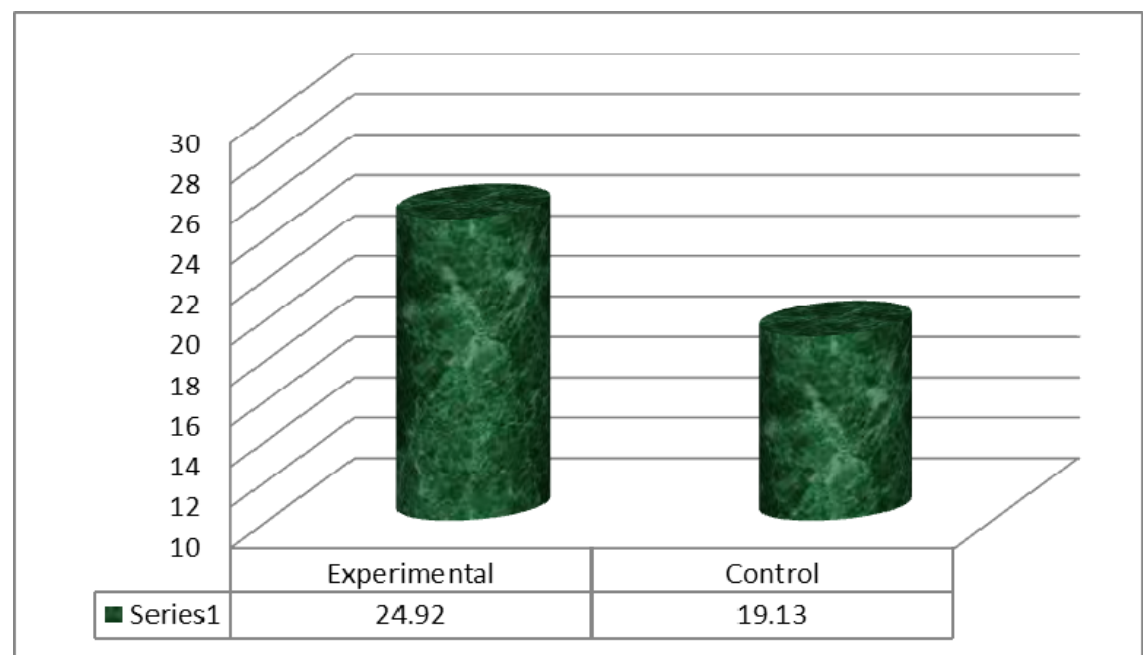

Figure 3. Means on posttest of reading comprehension by groups by pretest

\subsection{Instrument (Test) Analysis}

In order to approve of the efficiency of the utilized instruments, the researcher embarked on assessing the reliability and validity of the tests.

1. KR-21 Reliability Indices: As shown in Table 15, the KR-21 reliability indices for the pretests and posttests of self-directed learning and reading comprehension were $.95, .96, .79$, and .80 .

Table 15. KR-21 reliability indices

\begin{tabular}{llllll}
\hline & $\mathrm{N}$ & Mean & Std. Deviation & Variance & KR-21 \\
\hline Pre-SDL & 65 & 95.62 & 26.956 & 726.647 & .95 \\
Post-SDL & 65 & 112.57 & 30.862 & 952.437 & .96 \\
Pre-RC & 65 & 19.77 & 5.382 & 28.962 & .79 \\
Post-RC & 65 & 21.98 & 6.019 & 36.234 & .80 \\
\hline
\end{tabular}

2. Construct Validity: The researcher employed and ran Exploratory Factor Analysis (EFA) through the Varimax rotation to probe the underlying constructs of the tests employed in this study. Exploratory factor analysis assumes three important statistical concepts, say, sampling adequacy, lack of identity, and finally lack of singularity. That is to say, the sample size should be adequate for running the analysis, the correlation matrix should not have neither zero (identity) nor perfect (singularity) correlations among all variables. The Kaiser-Meyers (KMO) index of .494 was slightly lower than the minimum acceptable value of .50 ; however, there was no need to worry about the violation of this assumption, because all of factor loadings (Table 18 below) were higher than .50. (Field, 2013).

Table 16. KMO and Bartlett's Test

\begin{tabular}{lll}
\hline Kaiser-Meyer-Olkin Measure of Sampling Adequacy. & .494 \\
\hline \multirow{3}{*}{ Bartlett's Test of Sphericity } & Approx. Chi-Square & 208.973 \\
& Df & 10 \\
& Sig. & .000 \\
\hline
\end{tabular}

The significant results of the Bartlett's test $(\chi 2(10)=208.97, p=.000)$ indicated that the correlation matrix - as displayed in Table 16 - was significantly different from an identity one. Table 17 displays the correlation matrix 
used to run the factor analysis and the determinant statistic $(.033>.00001)$, indicating that there were not perfect correlations among all variables; hence, lack of singularity.

Table 17. Correlation matrix

\begin{tabular}{lllllll}
\hline \multirow{6}{*}{ Correlation } & & Proficiency & Pre-SDL & Post-SDL & Pre-RC & Post-RC \\
\hline \multirow{6}{*}{} & PET & 1.000 & .191 & .167 & .611 & .534 \\
& Pre-SDL & .191 & 1.000 & .840 & .218 & .214 \\
& Post-SDL & .167 & .840 & 1.000 & .230 & .395 \\
& Pre-RC & .611 & .218 & .230 & 1.000 & .835 \\
& Post-RC & .534 & .214 & .395 & .835 & 1.000 \\
\hline
\end{tabular}

a. Determinant $=.033$

Based on the indices obtained by KMO and Bartlet test, as well as correlation matrix, the researcher could run factor analysis. The SPSS extracted two factors that accounted for 83.59 percent of the variance. That is to say, the tests employed in this study measured two underlying traits with an accuracy of 83.59 percent.

Table 18. Total variance explained

\begin{tabular}{|c|c|c|c|c|c|c|c|}
\hline \multirow[b]{2}{*}{ Component } & \multicolumn{3}{|c|}{ Initial Eigenvalues } & $\begin{array}{l}\text { Extraction } \\
\text { Loadings }\end{array}$ & \multicolumn{2}{|c|}{ Ims of $\begin{array}{r}\text { Squared Rotation } \\
\text { Loadings }\end{array}$} & \multirow{2}{*}{$\begin{array}{l}\text { of Squared } \\
\text { of } \text { Cumulative \% }\end{array}$} \\
\hline & Total & $\begin{array}{l}\% \\
\text { Variance }\end{array}$ & of Cumulative $\%$ & $\begin{array}{l}\% \\
\% \text { Total } \\
\text { Variance }\end{array}$ & of Cumulative \% & 6 Total $\%$ Variance & \\
\hline 1 & 2.718 & 354.363 & 54.363 & 2.71854 .363 & 54.363 & 2.31646 .323 & 46.323 \\
\hline 2 & 1.461 & 29.228 & 83.591 & 1.46129 .228 & 83.591 & 1.86337 .268 & 83.591 \\
\hline 3 & .525 & 10.494 & 94.085 & & & & \\
\hline 4 & .224 & 4.484 & 98.569 & & & & \\
\hline 5 & .072 & 1.431 & 100.000 & & & & \\
\hline
\end{tabular}

As displayed in Table 19 and Figure 4, PET, pretest and posttest of reading comprehension loaded on the first factor that due to the nature of these tests can be labeled as "general language proficiency" factor.

Table 19. Rotated component matrix

\begin{tabular}{lll}
\hline & \multicolumn{2}{l}{ Component } \\
\cline { 2 - 3 } & 1 & 2 \\
\hline Pre-RC & .928 & \\
Post-RC & .884 & .951 \\
PET & .798 & .949 \\
Pre-SDL & & \\
Post-SDL & & \\
The pretest and posttest of self-directed learning loaded on the second factor which can be labeled as \\
"self-directed learning" factor.
\end{tabular}




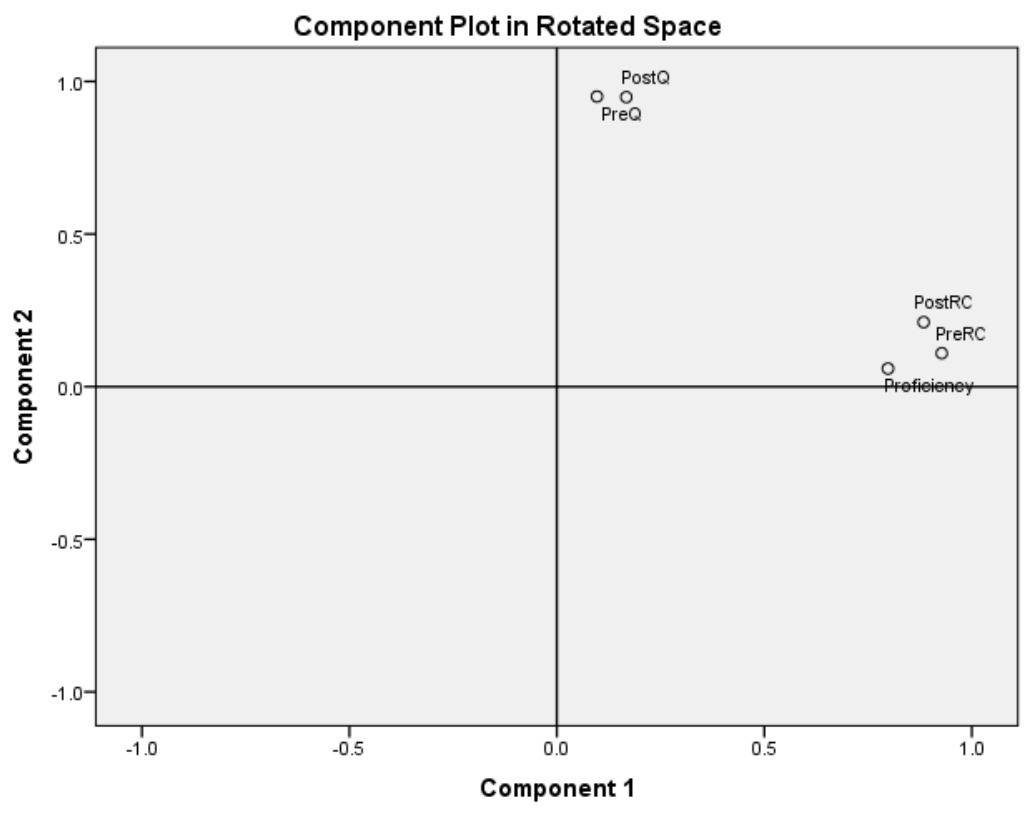

Figure 4. Component Plot 1. Factor loadings in rotated space

\subsection{Qualitative Analysis}

The researcher started this research by having one main question in mind, "what would a contemplative teaching class be like?" This question raised another question, "How does transformative education contribute to contemplative learning and teaching?"

Having such questions in mind, the researcher implemented portraiture as the prime techniques of contemplation in classroom. Based on what mentioned in the literature, portraiture refers to the detailed description and reporting of whatever happens in our daily life. It would allow us to monitor our previous mistakes to function better in similar situations we may come up in future.

As Lightfoot (1983) suggested, we learn much from scrutinizing deeply the stories of classroom life, which on it would inform more general educational processes. Portraiture has proven to be to the benefit of educational research, because it associates narrative inquiry with an empirical understanding of classroom contexts and processes (Lightfoot \& Davis, 1997). In contemplative teaching program, the teacher uses portraiture to assist learners to create their own stories of life events. This would improve their imagination, as well as the ability to reflect upon the realities of life, say, whatever happens about them.

Other way round, transformative learning aims at recognizing those human inner forces and desires that drive us towards reflection, dialogue, critique, discernment, action, and imagination. Thus, transformative learning is essentially a way of understanding adult learning as a meaning-making process aimed at fostering a democratic vision of society and self-actualization of individuals. Some educators, guided by more individual perspectives, argue that personal transformation precedes any meaningful, sustained social change. These changes lead us towards deep thinking and introspection about the people, event, and objects around us.

The researcher performed an interview with the students to find out some personal answers to the third question of this research, which goes, "What is the students' attitude toward self-directed learning?" Talking to more than 10 students, the researcher found that most of the students showed a positive attitude towards becoming self-directed learners who could study the lessons (reading texts) independently. This was done by the direct influence from the part of contemplative teaching. In contemplative teaching class, we focused on the physical movements and control over breathing in order to create an atmosphere to experience a sort of mental (mind) silence. Availing from such an atmosphere, the students could get rid of the negative thoughts and instead form positive mindset towards the events, people, and entities surrounding them. It is worth mentioning here that students, who experienced the class, started developing and forming stronger thoughts. Such thought frames helped them from and shape a stronger personality who could imagine doing things without the help of others. The interviews done during and after classes indicate such a fact. 
In an interview, Maryam said, "I would like to read more books all by myself, and I want the teacher to recommend some books for self-study". The researcher put no force or judgment on the students; therefore, it is safe to say that their ideas are not affected by the nature of the study.

In another view, with Hani the researcher found that Hani was significantly influenced by the techniques of contemplation in the classroom. Hani said, "Thinking is not an easy job. This has always been my problem in life. Honestly, I learnt to think better and I learnt to concentrate more deeply in life. This technique helped discover my inner potentials, so I started to develop the skills of learning that moved me towards become very independent."

In the other interviews, the researcher figured out that most students wanted to become self-directed learners; in other words, to hold positive attitude towards self-directed learning. It is self-evident that students faced a number of problems in contemplative teaching classrooms. Partly, these problems arise from the complications, conflicts, inhibitions, anxiety, and paradoxes found in the students' personalities and character. The rest of the problems they face in classroom may arise from the atmosphere created by both the researcher and teacher, because they had no previous experience in implementing contemplative teaching in classroom. The researcher found some facts about the classes by interviewing the candidates who took part in the experimental class. Talking to Fereshteh, Fariba, Maryam, Mojgan, and Sepideh, the MA students of TEFL, who were the passive participants in the contemplative class, the researcher could decode the following problems they faced throughout the course:

1). Deep thinking in half an hour is too hard.

2). The classroom was mostly teacher-centered not learner-centered.

3). We felt that were mostly followers, not leaders.

4). We had no idea of how to deal with cooperative learning.

5.) We mostly had individualistic attitudes, not social one, so we did not take part in discussions and teamwork

6). We had little desire to volunteer for the tasks, because we had the fear of doing it in a wrong way.

7). We cannot challenge our critical thinking, when the time comes.

8). Mostly, we felt shy in class, since our introvert part overcomes our extrovert character.

9). These problems arose along with all the efforts both the teacher and researcher made to change the class into collaborative one where they could experience independency and self-learning.

Regarding the last qualitative question, "In what ways does transformative education change classroom atmosphere?" the researcher has come up with the following conceptions that arise from her perceptions of the classroom procedures:

There is no doubt that, by implementing transformative learning atmosphere, we can encourage students to connect with one another in the same or a different class. Formal learning networks or support groups can be established, but generally, this kind of support works best, when students initiate it in their own way. Depending on the context, we can also suggest that students link up with discussion groups, professional associations, or other resources where people will have had experiences similar to theirs. Being open to perspectives different from our own can be remarkably problematic and demanding. Students may articulate their suppositions and muse over these ideas; however, they refrain when faced with accepting alternatives. What we did during our treatment was to try to create safe and enjoyable ways for students to try on different standpoints.

Lastly, we can help our students set up action plans for when they leave the course. This can be as simple as asking participants to write down two or three concrete things they will do, or it can be a more formal plan with goals, strategies for achieving those goals, and mechanisms for getting feedback from others. In some contexts, it may be possible to plan a follow-up meeting for participants to discuss, how they have acted on their transformation.

\section{Discussion}

In the quantitative phase of the present study, RQ1 asked "Does the application of contemplative teaching as a method in an EFL class reliably affect the students to turn into self-directed learners, as compared to students in conventional EFL classes?" and RQ2 asked "Does self-directed learning significantly improve students' reading comprehension skills, as compared to those students in conventional EFL classes?" The results of One-way ANCOVA revealed a significant difference between the means scores of the groups (Experimental Group versus Control Group) on the post-test of self-directed learning and reading proficiency; i.e., The participants in the 
Experimental Group benefited from contemplative teaching as contemplative teaching help them become more self-directed learners and more skilled L2 readers.

In the qualitative phase of the present study, RQ3 asked, "What is the students' attitude toward self-directed learning?" The coding and analysis of the interview data collected indicated that the participants held positive attitudes towards contemplative teaching and transformative learning. RQ4 asked, "What problems students might face within contemplative teaching setting?" The qualitative analysis indicated that, in the participants' opinions, the technique of contemplative teaching for language instruction would suffer some problems. The problems were more related to the teacher-centered nature of contemplative teaching, the confusion arising from the participants being required to think deeply, and lack of support from the classmates. Finally, RQ5 asked, "In what ways, does transformative learning and teaching change classroom atmosphere?" The participants in the Experimental Group talked in the interviews about the warming effects that these techniques had on L2 classroom atmosphere. In the following paragraphs, a discussion is presented as how the results should be interpreted. References are made to the previous related research to support the claims made.

This study supports the current thinking that contemplative teaching along with transformative instruction leads to conceptual, psychological and behavioral changes in learners' thinking order and autonomy (Boyer, Maher, \& Kirkman, 2006; Byrnes, 2012). In this line, Byrnes (2012) argued that transformative instruction affects the way that learners value the process of learning and increases their learning awareness and sensitivity which would determine how much they are willing to invest their resources (time, effort, money, etc.) in the process of learning. Boyer et al. (2006) claimed these conceptual modifications in learners' conceptual systems, resulting from contemplative teaching and transformative learning would lead to psychological accommodations and assimilations of learning metacognitive strategies. Finally, Danaher, Danaher, and Moriarty (2007) proposed that the changes in learners' conceptions and psychological dispositions would, in return, bring changes in the moment-to-moment learning strategies/behaviors, they employ in the classroom. According to Boyer et al. (2006), this movement from the changes in the conceptual learning system to changes in learning behaviors is the necessary step for a learner to reach learning autonomy and self-directed learning.

This interpretation is also supported in the fields of L2 teaching and learning (e.g., Cummins, 2000; Goulah, 2006, 2007; Kumaravadivelu, 2006). As the conceptual changes are concerned, the result can be interpreted as showing that the learners in the Experimental Group found the chance to reevaluate their conceptions of the processes involved in L2 learning. According to Cummins (2000) and Gan (2004), every language learner enters the language classroom with conceptions, as to how an L2 could be learned and these conceptions would fluctuate during the course of L2 instruction. Kumaravadivelu (2006) too argues that not only the learner has predetermined conceptions related to L2 learning, but also he/she would form a set of L2 learning metacognitive strategies to come up with the challenges of L2 learning (see O'Malley, Chamot, Stewner-Manzanares, Rtisso, \& Küpper, 1985, for a list of these strategies). The influences of these L2-related conceptions and strategies on the language learner are that they would influence the type of learning strategies and behaviors that L2 learners would employ to address the challenges of L2 learning (Goulah, 2006, 2007).

The point of the above argument is that, during the course of L2 learning, the learner would come to notice that he/she alone is responsible for his/her ultimate L2 achievements and, therefore, should take responsibility for them. Contemplative teaching and transformative instruction would lead the learner to this conclusion by providing him/her with a platform to practice critical thinking, questioning attitudes, and effective metacognitive strategies and learning strategies. In this fashion, the learner would become a more empowered, autonomous, and self-efficacious L2 learner that can self-direct his/her L2 learning attempts. Some researchers discuss that L2 achievements arising from this sense of L2 autonomy and self-directed L2 learning are more enduring and are better assimilated into the learner's interlanguage system (e.g., Mills, Pajares, \& Herron, 2007; Kormos, Kiddle, \& Csizér, 2011).

The results of the study also revealed a significant difference between the EFL learners' reading performance in the two different groups (i.e., the Experimental Group and the Control Group). Based on the results obtained, those students who received instruction via contemplative teaching program with the taste of transformative education outperformed those who received the conventional reading program. Apart from that, those students who developed more self-directed learning style than those who developed less, proved to be stronger in reading texts.

The above results can be interpreted as showing that contemplative teaching, transformation instruction, and self-directed L2 learning helped the Iranian EFL learners in the Experimental Group apply the knowledge gained from the tutorial class, and from their previous studies, to the reading comprehension posttest more effectively. 
This interpretation has been already predicted by Wallace (2003) who urged researchers to conceptualize L2 reading not in terms of learner-internal, cognitive factors, but rather in terms of social relations and power between the writer and the readers, or what Carter and Walker (1989) call the interpretative community of readers "within which readers grow up and are educated" (p. 3, as quoted in Wallace, 2003). Thus, according to Wallace (2003), reading success is determined by the extent that the EFL reader is equipped with the essential critical EFL awareness, interpretation skills, and historical, cultural, sociopolitical, and aesthetic perceptions needed to extract the meaning from the passage (also see Kumagai and Iwasaki , 2011 and Vieira, Moreira, and Peralta, 2014 for a similar argument). As it is related to the results of the present study, contemplative teaching and transformative instruction improved these dimensions for the participants in the Experimental Group and, thus, helped them have a better comprehension of, and performance on, the reading comprehension posttest.

The positive effects of contemplative teaching on EFL reading comprehension skills in the present study can also be attributed to the psychological and behavioral changes in the learner's interlanguage system discussed earlier. The psychological changes resulting from the implementation of contemplative teaching and transformative instruction might have had the participants in the Experimental Group reevaluate their awareness of metacognitive test-taking strategies for L2 reading comprehension. Zhang, Aryadoust, and Zhang (2014) pose an argument to claim that language learners deploy metacognitive test-taking strategies to take tests of L2 reading comprehension. Therefore, it could be the case that the participants in the Experimental Group succeeded in using more effective metacognitive strategies during the posttest of L2 reading comprehension in the present study.

Finally, the results of the qualitative stage in the present study indicated that the participants expressed positive attitudes towards contemplative teaching and transformative instruction and contended that these techniques would create a positive atmosphere in the classroom by encouraging the learners to connect with one another and support each other. Generally, these positive attitudes of the participants can be ascribed to the affective function that the techniques would serve for the participants in the Experimental Group. According Foster (1997) and Kumagai and Iwasaki (2011), transformative L2 teaching classroom contexts are essentially motivating in nature and, therefore, would encourage L2 learners to invest their resources more in the process of language learning. Reversely, L2 learners would value these contexts over traditional ones, when they come to see that they would experience more L2 learning achievements in these transformative contexts (Kumagai \& Iwasaki, 2011).

In contrast, the participants were also aware that any L2 teaching technique would suffer some limitations and contemplative teaching and transformative instruction were by no means an exception. The participants in the Experimental Group complained about the teacher-centered nature of their own EFL classroom that required them to follow the teacher's instructions. This is ironical, because the purpose of transformative instruction is exactly the opposite; i.e., transformative instruction aims to help learners lead and self-direct their own learning attempts (see Cummins, 2000). This irony is understandable, if look more deeply into the premises of contemplative teaching and transformative instruction (e.g., Illeris, 2014; Kumashiro, 2004; Sanprasert, 2010). Transformative instruction is about learners trying to win their autonomy and independence over rather than the teacher generously granting them to the learners. (Illeris, 2014; Kumashiro, 2004)

The participants also mentioned some problems that they experienced during the contemplative teaching course. According to the participants, they found deep thinking too hard during cooperative learning was sometimes confusing for them, and their classmates were not sometimes supportive. These problems could demotivate the participants as some of them had experienced fears of failure and shyness and had been unable to deploy their critical thinking in sessions of contemplative and transformative L2 teaching. It is hypothesized that these limitations bring us back to the authoritative role of the L2 teacher in contemplative and transformative instruction. According to Sanprasert (2010), the authoritative role of the language teacher at the early stages of instruction does not only seem inevitable, but it is also desirable as, at these stages, learners are confused about what is going on in the classroom; the authoritative role of teacher serves a classroom-management function which would ultimately guide the learners towards thorough L2 autonomy, independence, and self-directed learning.

\section{Conclusion, Implications, and Suggestions for Further Research}

\subsection{Conclusion}

The results of the study indicated that contemplative teaching, accompanied with transformative instruction, would in fact have significant effects on Iranian EFL learners' L2 autonomy, i.e., self-directed L2 learning, and L2 reading comprehension skills. As its effects on self-directed L2 learning were concerned, the results were interpreted as showing that contemplative teaching and transformative instruction would exert changes to L2 
learners' conceptual and psychological predispositions that, in return, would determine the strategies and behaviors the learners employ to address the challenges of L2 learning. During the courses of these changes, learners would come to notice that they are the causative agent for their own L2 learning and, thus, they should take full responsibility for it. In the present study, contemplative teaching helped the Iranian learners reach this conclusion by making them more empowered L2 learners who found the chance for critical thinking, deep thinking, questioning attitudes, and the reassessment of their metacognitive strategies and learning strategies. Thus, as far as its effects on L2 self-directed learning were concerned, it could be concluded that contemplative L2 teaching improved the sense of autonomy and self-efficacy for the participants in the Experimental Group who found themselves free from being fully directed by their language teacher and became self-directed L2 learners.

In the present study, contemplative and transformative L2 instruction also helped the participants in the Experimental group perform significantly better than those in the Control Group on the L2 reading comprehension posttest. This result showed that contemplative and transformative L2 instruction had led the former group of participants (i.e., the Experimental Group) improve their critical thinking skills, critical EFL awareness, and interpretations skills which, according to the Wallace's (2003) conceptualization of L2 reading as a social activity, are the prerequisite for proficient comprehension of L2 reading texts. Further, it was hypothesized that, along the psychological and behavioral changes resulting from contemplative and transformative L2 instruction that led to self-directed, autonomous learning, the participants in the Experimental Group reevaluated their cognitive and metacognitive L2 reading strategies. This reevaluation might have caused them to perform better on the L2 reading comprehension posttest than the participants who were instructed through the traditional L2 teaching method.

The analysis of the interview data collected in the present study indicated that the participants in the Experimental Group held positive attitudes towards contemplative and transformative L2 instruction and believed these instructional strategies would create a supporting and viable classroom atmosphere. These results show that contemplative and transformative instruction is motivating in nature that would cause language learners to invest their resources more in the process of L2 learning. Finally, the analysis showed that, like any other L2 teaching technique and strategy, contemplative teaching would suffer some limitations. The point was that the EFL learners in the present study were aware of these limitations and contended that the limitations might hinder the benefits they could enjoy from these L2 teaching strategies.

\subsection{Implications of the Study}

The findings of the present study would have significant implications for both theory and practice on L2 contemplative teaching, self-directed learning, and reading comprehension. As the theoretical implications are concerned, the findings would provide an answer to the long-debated question of how L2 learners can be helped to move from being fully directed to being self-directed in their L2 learning attempts by claiming that contemplative L2 teaching can be a good strategy for this purpose. The present study supported this claim by presenting a rationale as to how contemplative teaching would contribute to L2 self-directed learning. On the other hand, the findings would increase our understanding of how contemplative teaching would improve EFL learners' L2 reading comprehension skills. The findings indicated that contemplative and transformative instruction would do so through raising learners' critical awareness and interpretation skills that are the necessary skills for successful L2 reading comprehension (Wallace, 2003).

As far as the L2 pedagogy are concerned, the findings would propose the implications that contemplative L2 teaching would provide EFL learners with a platform to practice critical thinking skills which would lead to L2 learning autonomy and self-directed learning. Further, EFL learners find the opportunity to develop a repertoire of effective cognitive and metacognitive strategies for L2 reading comprehension, because of contemplative and transformative instruction. Thus, language teachers are strongly encouraged to employ contemplative teaching techniques in their language classrooms and foster critical thinking, consciousness, and metacognitive strategies in their learners to help them become autonomous and self-directed L2 learners. Finally, the findings indicated that the Iranian EFL learners held positive attitudes towards contemplative and transformative instruction while, at the same time, complained about the limitations of these L2 teaching techniques. L2 teachers are recommended to invest on these learners' positive attitudes and try to alleviate the limitations to encourage their L2 learners more to take advantages of the benefits recommended by contemplative teaching and self-directed learning.

\subsection{Suggestions for Future Research}

Contemplative teaching is a rather new issue in the field of language teaching and more studies should be 
conducted, before making claims about its effects on L2 achievements. Thus, a few suggestions are made to help willing researchers examine contemplative teaching and self-directed learning in their future studies.

First, the present study compared the effects of contemplative teaching versus the effects of a traditional method on L2 self-directed learning and reading comprehension skills and the results indicated that the positive effects of the former could be substantiated. However, it is also important to investigate the relative merit of contemplative L2 teaching against other competing methods and approaches which have been found to exert positive effects L2 learning such as Experiential Learning (Kohonen et al. 2014), project-based learning (Grode \& Stacy, 2015), and metacognitive instruction (Victori \& Lockhart, 1995). This is important, because practical limitations (e.g., time, resources, etc.) mean that teachers have to make the best instructional choices in their classrooms and the choices should be informed by research findings. Thus, it is suggested that the effects of contemplative teaching be compared with the effects of other L2 instructional strategies to determine if contemplative and transformative instruction would be more fruitful.

Second, the present study delimited L2 achievements to L2 reading comprehension; future studies are recommended to examine the effects of contemplative teaching on other L2 skills (listening, speaking, and writing) and components (grammar and vocabulary).

Third, the role of individual differences in self-directed learning has been largely neglected in the field of L2 acquisition research, except for L2 learner autonomy (e.g., Ho \& Crookall, 1995; Oxford, 2003). Thus, it is suggested that researchers would pay more attention to individual differences (e.g., anxiety, self-confidence, willingness to communicate, etc.) in their future research on contemplative teaching, transformative instruction, and L2 self-directed learning.

Finally, the present study investigated the attitudes the participants held towards contemplative L2 teaching, the limitations of the technique from the participants' viewpoints, and its positive effects on L2 classroom atmosphere; however, the study did these in separate compartments. Grounded theory would provide researchers with the opportunity to analyze qualitative data through a single framework and, thus, it is suggested that the future studies adopt a grounded-theory framework to analyze the qualitative data on contemplative and transformative L2 instruction.

\section{References}

Boyer, N. R., Maher, P. A., \& Kirkman, S. (2006). Transformative learning in online settings: The use of self-direction, metacognition, and collaborative learning. Journal of Transformative Education, 4(4), 335-361. https://doi.org/10.1177/1541344606295318

Byrnes, K. (2012). A portrait of contemplative teaching: Embracing wholeness. Journal of Transformative Education, 10(1), 22-41. https://doi.org/10.1177/1541344612456431

Carter, R., \& Walker, R. (1989). Literature and the learner: introduction to literature and the learner: methodological approaches. London: the British Council.

Cummins, J. (2000). Academic language learning, transformative pedagogy, and information technology: Towards a critical balance. TESOL Quarterly, 34(3), 537-548. https://doi.org/10.2307/3587742

Danaher, P. A., Danaher, G., \& Moriarty, B. (2007). Interrogating learner-centeredness as a vehicle for meaning emerging in practice and researching personal pedagogies: Transformative learning, self-efficacy and social presence at two Australian universities. International Journal of Pedagogies and Learning, 3(3), 4-13. https://doi.org/10.5172/ijpl.3.3.4

Dörnyei, Z. (2005). The psychology of the language learner. Mahwah, NJ: Lawrence Erlbaum. https://doi.or $\mathrm{g} / 10.1177 / 0261927 \mathrm{X} 05281424$

Field, A. (2013). Discovering statistics using IBM SPSS statistics. New York: Sage.

Foster, E. (1997). Transformative learning in adult second language learning. New Directions for Adult and Continuing Education, 74, 33-40. https://doi.org/10.1002/ace.7404

Gan, Z. (2004). Attitudes and strategies as predictors of self-directed language learning in an EFL context. International Journal of Applied Linguistics, 14(3), 389-411. https://doi.org/10.1111/j.1473-4192. 2004.00071.x

Goulah, J. (2006). Transformative second and foreign language learning for the 21st century. Critical Inquiry in Language Studies: An International Journal, 3(4), 201-221. https://doi.org/10.1207/s15427587clis0304_1

Goulah, J. (2007). Village voices, global visions: Digital video as a transformative foreign language-learning tool. 
Foreign Language Annals, 40(1), 62-78. https://doi.org/10.1111/j.1944-9720.2007.tb02854.x

Grode, J., \& Stacy, A. (2015). Authentic materials and project-based learning. In D. Nunan, \& J. C. Richards (Eds.), Language learning beyond the classroom (pp.171-179). Edinburgh: Routledge.

Hatch, E., \& Farhady, F. (1982). Research Design and Statistics for Applied Linguistics. Rowley, Mass: Newbury House

Ho, J., \& Crookall, D. (1995). Breaking with Chinese cultural traditions: Learner autonomy in English language teaching. System, 23(2), 235-243. https://doi.org/10.1016/0346-251X(95)00011-8

Houle, C. O. (1961). The inquiring mind (p. 23). Madison: University of Wisconsin Press.

Illeris, K. (2014). Transformative learning and identity. Journal of Transformative Education, 12(2), 148-163. https://doi.org/10.1177/1541344614548423

Knowles, M. S. (1975). Self-directed Learning: A Guide for Learners and Teachers. Chicago: Follett.

Kohonen, V., Jaatinen, R., Kaikkonen, P., \& Lehtovaara, J. (2014). Experiential learning in foreign language education. Edinburgh: Routledge. https://doi.org/10.4324/9781315840505

Kormos, J., Kiddle, T., \& Csizér, K. (2011). Systems of goals, attitudes, and self-related beliefs in second-language-learning motivation. Applied Linguistics, 32(5), 495-516. https://doi.org/10.1093/app lin/amr019

Kumagai, Y., \& Iwasaki, N. (2011). What it means to read 'critically' in a Japanese language classroom: Students' perspectives. Critical Inquiry in Language Studies, 8(2), 125-152. https://doi.org/10.1080/15427 587.2011.571277

Kumaravadivelu, B. (2006). Understanding language teaching: From method to postmethod. London: Routledge.

Kumashiro, K. K. (2004). Against common sense: teaching and learning toward social justice. New York: Routledge.

Long, H. B. (2005). Skills for Self-directed Learning. Norman, OK: University of Oklahoma.

Mills, N., Pajares, F., \& Herron, C. (2007). Self-efficacy of college intermediate French students: Relation to achievement and motivation. Language Learning, 57(3), 417-442. https://doi.org/10.1111/j.1467-99 22.2007.00421.x

O’Malley, J., Chamot, A., Stewner-Manzanares, G., Rtisso, R., \& Küpper, L. (1985). Learning strategy applications with students of English as a second language. TESOL Quarterly, 19(3), 557-584. https://doi. org $/ 10.2307 / 3586278$

Oxford, R. L. (2003). Toward a more systematic model of L2 learner autonomy. In D. Palfreyman, \& R., C. Smith (Eds.), Learner autonomy across cultures: Language education perspectives (pp. 75-91). Basingstoke, England: Palgrave Macmillan.

Stevens, L. P. (2009). Maps to interrupt a pathology: Immigrant populations and education. Critical Inquiry in Language Studies, 6(1-2), 1-14. https://doi.org/10.1080/15427580802679245

Tough, A. (1971). The adult's learning projects. Toronto: Ontario Institute for Studies in Education.

Victori, M., \& Lockhart, W. (1995). Enhancing metacognition in self-directed language learning. System, 23(2), 223-234.

Vieira, F., Moreira, M. A., \& Peralta, H. (2014). Research in foreign language education in Portugal (2006-2011): Its transformative potential. Language Teaching, 47(02), 191-227. https://doi.org/10.1017/S02614448130 00529

Zhang, L., Aryadoust, V., \& Zhang, L. J. (2014). Development and Validation of the Test Takers' Metacognitive Awareness Reading Questionnaire (TMARQ). The Asia-Pacific Education Researcher, 23(1), 37-51. https://doi.org/10.1007/s40299-013-0083-z

\section{Copyrights}

Copyright for this article is retained by the author(s), with first publication rights granted to the journal.

This is an open-access article distributed under the terms and conditions of the Creative Commons Attribution license (http://creativecommons.org/licenses/by/4.0/). 